\title{
SUBCELL LIGHT CURRENT-VOLTAGE CHARACTERIZATION OF IRRADIATED MULTIJUNCTION SOLAR CELL
}

\author{
Don Walker, John Nocerino, Yao Yue, Colin J. Mann, and Simon H. Liu
}

The Aerospace Corporation, 2310 E. El Segundo Blvd., El Segundo, CA 90245, U.S.A, Email: don.walker@aero.org

\begin{abstract}
The degradation of individual subcell $\mathrm{J}-\mathrm{V}$ parameters, such as short circuit current, open circuit voltage, fill factor, and power of a GaInP/GaInAs/Ge triple junction solar cell by $1 \mathrm{MeV}$ electrons were derived utilizing the spectral reciprocity relation between electroluminescence and external quantum efficiency. After exposure to a fluence of $1 \times 10^{15} 1 \mathrm{MeV}$ electrons, it was observed that up to $67 \%$ of the voltage loss is from the middle, GaInAs subcell. Also, the dark saturation current of the Ge and GaInAs subcells increased but a simultaneous decrease in ideality factor caused a reduction of the open circuit voltage. The reduced ideality factor further indicates a change in the primary recombination mechanism.
\end{abstract}

\section{INTRODUCTION}

Understanding the effects that influence the currentvoltage (I-V) characteristics of space photovoltaics is critical to predicting their on-orbit performance[1-3]. By investigating the effects of space radiation on the underlying device parameters we can better understand and predict the performance of on-orbit solar arrays. Current state-of-the-art solar cells are made from direct bandgap III-V materials because of their high efficiency and radiation hardness. Multijunction solar cells are more radiation hard than previous generation single junction gallium arsenide ( $\mathrm{GaAs}$ ) solar cells due to the radiation hardness of the current limiting indium gallium phosphide based top cell[4]. While current degradation can be tuned for and characterized by quantum efficiency measurements, it has only been recently discovered that the open circuit voltage of each subcell of a monolithic GaInP/GaInAs/Ge can be derived along with the partial dark and light currentvoltage parameters. By utilizing the reciprocity theorem between electroluminescence and external quantum efficiency [5], the subcell dark and light current-voltage curves can be derived before and after irradiation [6-8]. From the subcell dark and light current-vottage curves we can determine the radiation induced degradation of each subcell's short circuit current, open circuit voltage, fill factor, power, ideality, and dark saturation current by $1 \mathrm{MeV}$ electrons at a fluence of $1 \times 10^{15}$ electrons $/ \mathrm{cm}^{2}$. The ability to measure all the degradation current-voltage parameters of each subcell can lead to better degradation modelling. Understanding how each subcell degrades in voltage adds a new dimension of potentially tuning for less voltage degradation after particle irradiation

\section{EXPERIMENT}

Triple-junction ATJ solar cells of GaInP/GaInAs/Ge were purchased from SolAero Technologies $\AA$. The solar cells were $2 \mathrm{~cm} \times 2 \mathrm{~cm}$ and did not have a coverglass. Light current-voltage, quantum efficiency, and electroluminescence measurements were performed before and after electron radiation at The Aerospace Corporation's Photovoltaic Evaluation And Research Laboratory (PEARL). The short circuit current density $\left(\mathrm{J}_{\mathrm{sc}}\right)$, open circuit voltage $\left(\mathrm{V}_{\mathrm{oc}}\right)$, fill factor, and efficiency were determined under a calibrated AM0 solar simulator on a temperature-controlled stage at $301.15 \mathrm{~K}\left(28^{\circ} \mathrm{C}\right)$. The simulator was calibrated using ATJ primary, JPL balloon flown standards. Quantum efficiency measurements were conducted using a Newport monochromator that was calibrated using a silicon photodiode and InGaAs diode that are National Institute of Standards and Technology traceable. Electroluminescence measurements were also performed at $301.15 \mathrm{~K}$ using a Horiba monochromator with a $2 \mathrm{~d}$, thermoelectrically cooled silicon CCD, and a temperature controlled, liquid nitrogen cooled extended InGaAs linear array. Electron radiation was conducted at the National Institute of Standards and Technology radiation facility. The triple junction cells were exposed to electrons at an energy of $1 \mathrm{MeV}$ and a fluence of $1 \mathrm{x}$ $10^{15}$ electrons $/ \mathrm{cm}^{2}$.

\section{RESULTS AND DISCUSSION}

The spectral reciprocity relation as defined by Eq. 1 relates the external luminescence $\left(\phi_{e m}\right)$ and quantum efficiency $\left(Q_{e}\right)$ to the voltage $(V)$ of a solar cell, where $\phi_{b b}$ is the black body photon flux, $q$ is the electron charge, $k$ is the Boltzmann constant, and $T$ is temperature. By taking electroluminescence spectra of each junction in a multijunction solar cell at different injection currents you can calculate the voltage of each subcell at each injection current. The open circuit voltage of each subcell is derived from the voltage calculated using Eq. 1 at an injection current equal to the short circuit current of the individual subcell.

$$
\phi_{e m}=Q_{e} \phi_{b b}\left[e^{\frac{q V}{k T}}-1\right]
$$

The electroluminescence of each junction was taken before and after irradiating the triple junction cell with a 
fluence of $1 \times 10^{15} 1 \mathrm{MeV}$ electrons $/ \mathrm{cm}^{2}$ as can be seen in Fig. 1. The electroluminescence spectrum of each junction was taken at injection current densities logarithmically ranging over approximately 25 points from $25 \mu \mathrm{A} / \mathrm{cm}^{2}$ to $35 \mathrm{~mA} / \mathrm{cm}^{2}$. After exposure, to electron radiation, it is observed in Fig. 1a that the electroluminescence of GaInP and GaInAs is reduced by over two orders of magnitude. Also, the relative peak intensity between GaInP and GaInAs changes such that GaInP is brighter than GaInAs. The electroluminescence of the Ge subcell also decreases, losing about half of its electroluminescence. Also, the luminescence below $1400 \mathrm{~nm}$ is quenched after electron radiation. The luminescence below 1400 is believed to be from direct transfer states in the Ge.
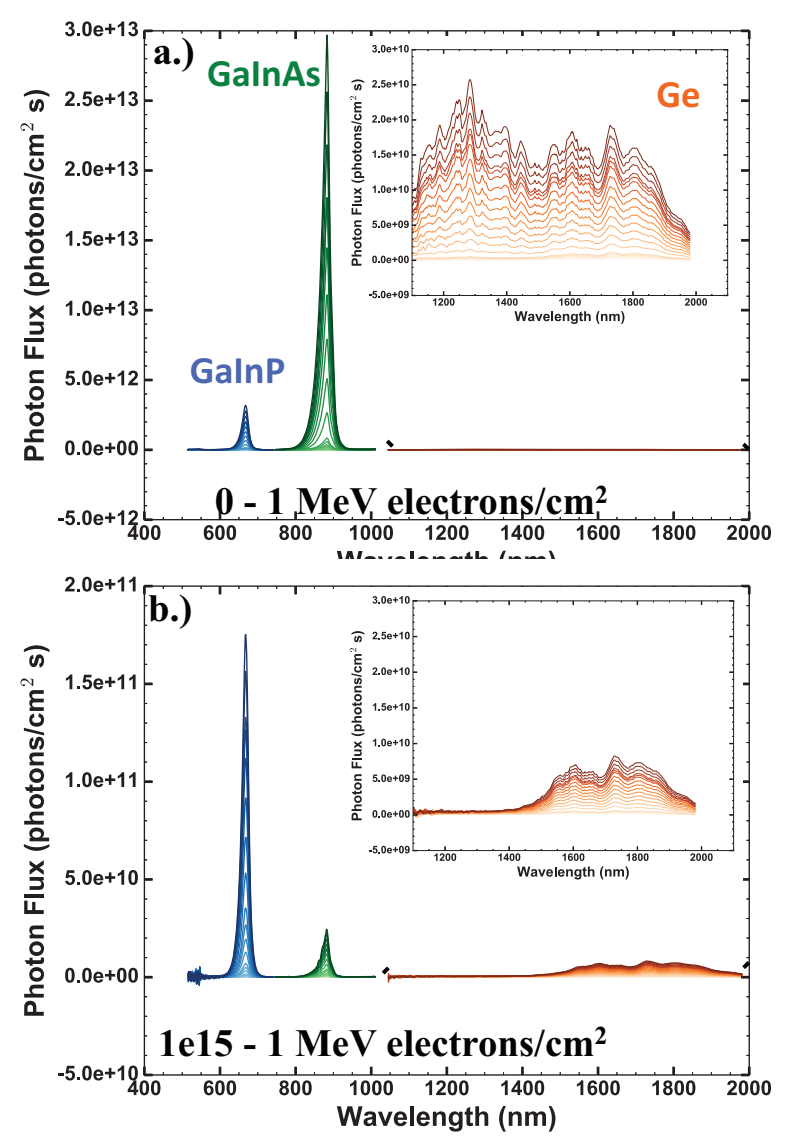

Figure 1. Electroluminescence of GaInP, GaInAs, and Ge subcells in a triple junction solar cell before irradiation with $1 \mathrm{MeV}$ electrons (a.) and after a fluence of $1 \times 10^{15} 1 \mathrm{MeV}$ electrons $/ \mathrm{cm}^{2}$ (b.).

By using the reciprocity relation we can calculate the voltage of each subcell for each injection current and derive subcell dark current-voltage characteristics for each subcell before and after electron radiation as seen in Fig 2. The most obvious observed change is an increase in the dark current for each subcell at any given voltage. Less obvious, is the change in ideality of each subcell as well as the change in the saturation current density. By fitting the subcell dark current-voltage curves, we can see that ideality becomes more ideal, closer to 1 from the Ge and GaInAs subcell (Tab. 1).

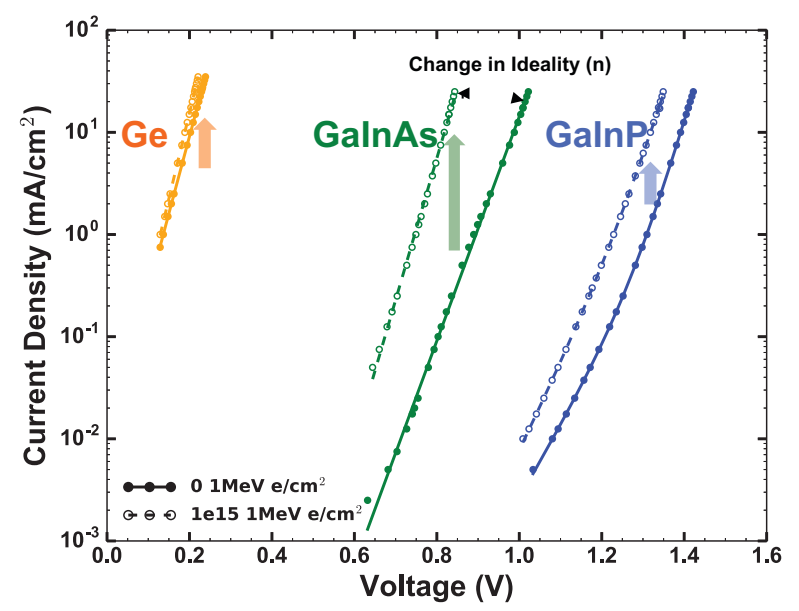

Figure 2. Dark current-voltage properties before and after irradiation with $1 \times 10^{15} 1 \mathrm{MeV}$ electrons $/ \mathrm{cm}^{2}$. The dark current-voltage curves were derived by using the spectral reciprocity relationship. The GaInAs subcell showed the greatest increase in dark current. Also, the GaInAs and Ge subcells had a decrease in their respective ideality factor.

The decrease in ideality indicates that the subcells are becoming more dominated by radiative recombination after irradiation, albeit there is much less radiative recombination as indicated by the electroluminescence spectra.

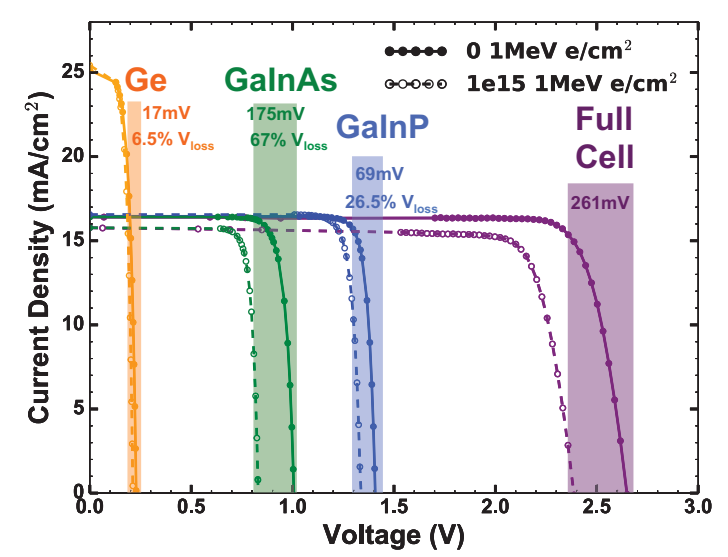

Figure 3. The subcell light current-voltage properties are derived by using superposition. The photocurrent derived from the respective quantum efficiency spectrum and the AMO spectra were used to derive the subcell light current-voltage properties pre and post irradiation with $1 \times 10^{15} 1 \mathrm{MeV}$ electrons $/ \mathrm{cm}^{2}$.

Finally, by offsetting the dark current-voltage curves using the derived photocurrent from integrating the AM0 spectrum with the quantum efficiency spectrum 
Table 1

\begin{tabular}{ccccccccc}
\hline $1 \mathrm{MeV} \mathrm{e}$ & Cell & $\mathrm{J}_{\mathrm{sc}}\left(\mathrm{mA} / \mathrm{cm}^{2}\right)$ & $\mathrm{ff}$ & $\mathrm{P}_{\max }(\mathrm{W})$ & $\mathrm{V}_{\text {oc }}(\mathrm{volts})$ & $\mathrm{V}_{\text {loss }}(\%)$ & $\mathrm{J}_{\mathrm{o}}\left(\mathrm{mA} / \mathrm{cm}^{2}\right)$ & $\mathrm{n}$ \\
\hline \multirow{3}{*}{0} & Full & 16.42 & 0.84 & 0.147 & 2.65 & & & \\
& $\mathrm{~J}_{1}$ & 17.30 & 0.88 & 0.086 & 1.41 & & $3.75 \mathrm{E}-19$ & 1.20 \\
& $\mathrm{~J}_{2}$ & 17.26 & 0.83 & 0.058 & 1.01 & & $1.50 \mathrm{E}-10$ & 1.52 \\
& $\mathrm{~J}_{3}$ & 26.44 & $0.64^{*}$ & $0.016^{*}$ & 0.23 & & $8.88 \mathrm{E}-03$ & 1.11 \\
\hline \multirow{4}{*}{$1 \times 10^{15}$} & & & & & & & & \\
& Full & 15.78 & 0.83 & 0.124 & 2.39 & & & \\
& $\mathrm{~J}_{1}$ & 17.16 & 0.87 & 0.080 & 1.34 & 26.45 & $2.11 \mathrm{E}-17$ & 1.26 \\
& $\mathrm{~J}_{2}$ & 16.34 & 0.85 & 0.046 & 0.83 & 67.06 & $4.44 \mathrm{E}-11$ & 1.21 \\
\hline \hline
\end{tabular}

Table I. The measured and derived light current-voltage properties of a multijunction solar cell (Full) its subcells $\left(J_{1}\right.$, $J_{2}$, and $J_{3}$ ) before and after irritation with $1 \times 10^{15} 1 \mathrm{MeV}$ electrons $/ \mathrm{cm}^{2}$. The dark current-voltage parameters for each subcell are also presented. (*These values were calculated and presented for completion, but have error associated with not being able to capture the full 'knee' of the subcell current-voltage curve.)

we can produce light current-voltage curves for each subcell. As can be seen in Fig. 3 and Tab. 1, the subcell fill factors, Voc, Jsc, and power. Previously, this has not been accomplished as the lower injection currents needed to obtain the knee of the current-voltage curve had not been obtained [7, 8]. Utilizing the derived subcell voltages we can now determine where the greatest loss in voltage comes from in the multijunction solar cell by evaluating the $V_{i_{\text {loss }}}$ factor as described in Eq. 2.

$$
V_{i_{\text {loss }}}=\frac{\Delta V_{i}}{\Delta V_{\text {Total Loss }}}=\frac{V_{i_{0}}-V_{i_{1 e 15}}}{V_{0}-V_{1 e 15}}
$$

In Eq. 2, $V_{i_{\text {loss }}}$ is the normalized voltage loss for each junction $(i) . \quad V_{i_{\text {loss }}}$ is simply a way to determine what subcell contributes to the greatest loss in voltage of the multijunction solar cell. In this case the GaInAs contributes $67.06 \%$ of the voltage loss, GaInP contributes $26.45 \%$, and Ge contributes $6.49 \%$ of the loss.

\section{CONCLUSION}

By deriving the subcell current-voltage properties and characterizing their radiation induced degradation, we can now identify where most of the voltage is coming from, radiation effects on fill factor, as well as the root cause for voltage degradation in multijunction solar cells. The ability to measure the degradation of subcell current-voltage properties has implications in better predicting radiation degradation of space photovoltaics, as well as developing more radiation hard solar cells.

\section{REFERENCES}

1. H. Y. Tada, J. R. Carter, B. E. Anspaugh, and R. G. Downing, "Solar cell radiation handbook," Jet Propulsion Laboratory, California Institute of Technology 82-69, 1982.

2. B. E. Anspaugh, "GaAs solar cell radiation handbook," Jet Propulsion Laboratory, California
Institute of Technology 96-9, 1996.

3. K. C. Reinhardt, C. S. Mayberry, B. P. Lewis, and T. L. Kreifels, "Multijunction solar cell iso-junction dark current study," in Photovoltaic Specialists Conference, 2000. Conference Record of the Twenty-Eighth IEEE, 2000, pp. 1118-1121.

4. K. C. Reinhardt, Y. K. Yeo, P. H. Ostdiek, and R. L. Hengehold, "Junction characteristics of electronirradiated $\mathrm{Ga}_{0.5} \mathrm{In}_{0.5} \mathrm{P} \mathrm{n}+\mathrm{p}$ diodes and solar cells," Journal of Applied Physics, vol. 81, pp. 3700-3706, 1997.

5. T. Kirchartz and U. Rau, "Detailed balance and reciprocity in solar cells," Physica Status Solidi aApplications and Materials Science, vol. 205, pp. 2737-2751, Dec 2008.

6. T. Kirchartz, U. Rau, M. Hermle, A. W. Bett, A. Helbig, and J. H. Werner, "Internal voltages in $\mathrm{GaInP} / \mathrm{GaInAs} / \mathrm{Ge}$ multijunction solar cells determined by electroluminescence measurements," Applied Physics Letters, vol. 92, Mar 2008.

7. S. Roensch, R. Hoheisel, F. Dimroth, and A. W. Bett, "Subcell I-V characteristic analysis of gainp/gainas/ge solar cells using electroluminescence measurements," Applied Physics Letters, vol. 98, Jun 2011.

8. R. Hoheisel, F. Dimroth, A. W. Bett, S. R. Messenger, P. P. Jenkins, and R. J. Walters, "Electroluminescence analysis of irradiated GaInP/GaInAs/Ge space solar cells," Solar Energy Materials and Solar Cells, vol. 108, pp. 235-240, Jan 2013. 